\title{
Poroma of the Eyelid: A Rare Site of Occurrence
}

\author{
Urmil Chawla $^{1}$, Khurana $\mathrm{AK}^{2}$, Jyoti Deswal ${ }^{3 *}$, Bhawna Khurana ${ }^{4}$, Hemlata T Kamra ${ }^{5}$ \\ ${ }^{1}$ Professor, Regional Institute of Ophthalmology, PGIMS, Rohtak, Haryana, India \\ ${ }^{2}$ Senior Professor, Regional Institute of Ophthalmology, PGIMS, Rohtak, Haryana, India \\ ${ }^{3}$ Assistant Professor, Regional Institute of Ophthalmology, PGIMS, Rohtak, Haryana, India \\ ${ }^{4}$ Assistant Professor, Department of Ophthalmology, SGRR Institute of Medical and Health Sciences, Dehradun, Uttrakhand, India \\ ${ }^{5}$ Professor, Department of Pathology, Kalpana Chawla Government Medical College and Hospital, Karnal, Haryana, India
}

\section{DOI:10.36348/SJMPS.2019.v05i09.007}

| Received: 31.08.2019 | Accepted: 09.09.2019 | Published: 20.09.2019

*Corresponding author: Jyoti Deswal

\section{Abstract}

A clinicopathological case report of a woman with an unusual right lower eyelid lesion is presented. The lesion was a slow growing ulcerated nodule over the eyelid clinically simulating a basal cell carcinoma, however unexpectedly the biopsy revealed the growth to be an eccrine poroma. Sweat glands occur commonly on the eyelids and eccrine poroma should be considered in the differential diagnosis of eyelid tumours.

Keywords: Eccrine poroma, intercellular bridges, poroid cells.

Copyright @ 2019: This is an open-access article distributed under the terms of the Creative Commons Attribution license which permits unrestricted use, distribution, and reproduction in any medium for non-commercial use (NonCommercial, or CC-BY-NC) provided the original author and source are credited.

\section{INTRODUCTION}

Eccrine poromas are benign, slow-growing solitary tumors which originate from the intraepidermal portion of the eccrine sweat duct. This tumor had once been known to arise in bare skin of the palms and the soles, but recently it has become clear that this tumor can arise on any skin surface with sweat gland [1].

Benign eccrine poromas have very rarely been reported to occur on the eyelid. So we reviewed the literature and report an extremely rare case of an eccrine poroma developing on the eyelid, which may be considered as first case reported from India

\section{CASE REPORT}

A 71-year-old Indian woman presented at our hospital in November 2018 with a painless slowgrowing, medium sized lesion on the medial half of her right lower eyelid of 1-year duration. The lesion was well circumscribed, centrally ulcerative, reddish-pink and $8 \times 9 \mathrm{~mm}$ in size (Fig. 1, 2). The margins of the ulcerated area were undermined and the floor showed healthy granulation tissue. She had no history of trauma or insect bite.

An ophthalmic examination revealed nothing abnormal except for early lenticular opacities and the patient's BCVA was 6/12 in both eyes. A General Physical Examination conducted also showed nothing abnormal. There was no enlargement of auricular, cervical or submandibular lymph nodes. USG of abdomen and lungs was also found to be normal.

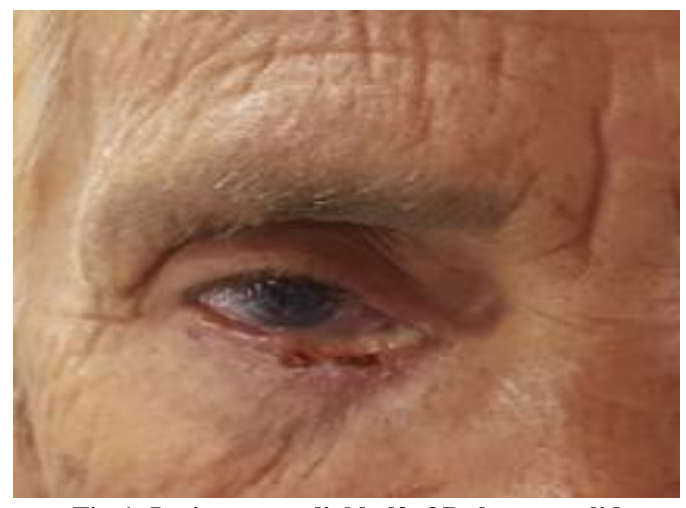

Fig-1: Lesion on medial half of Rt.lower eyelid

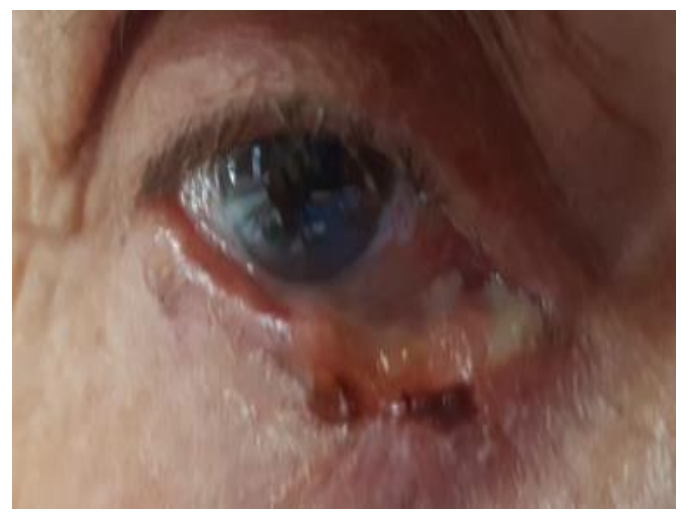

Fig-2: Magnified view of lesion 
Clinically the lesion was suspected to be a basal cell carcinoma. It was managed surgically by performing an excision biopsy under local anaesthesia. The lesion was marked including $3 \mathrm{~mm}$ of tumor free margin all around.(Fig 3a) Excision of the lid mass leaving behind only small portions of lower lid margin medially and laterally was done resulting in a large surgical lid coloboma (Fig 3b). The lid reconstruction was done with the help of Tenzel semicircular flap (Fig 3c) alongwith local advancement flap (Fig 4a). Suturing was completed in two layers with the help of 6-0 vicryl and 6-0 silk sutures (Fig 4b).The excised mass was sent for histopathological examination. Postoperative results at 4 wks were satisfactory (Fig 4c).

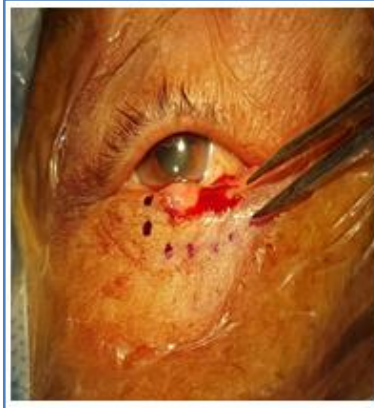

a

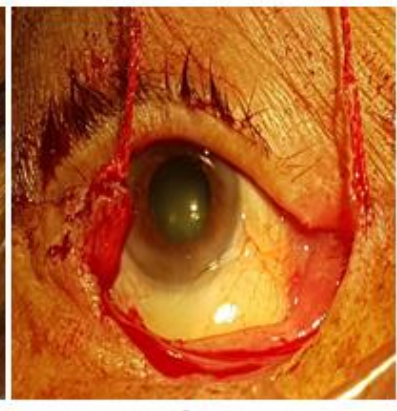

b

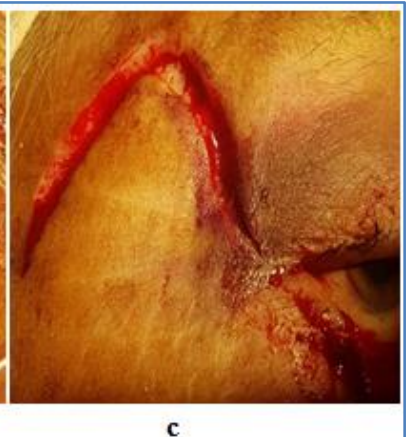

Fig-3a: marking the boundaries of the lesion leaving $3 \mathrm{~mm}$ of tumour free margin. 3b: Large surgical defect created. 3c: Tenzel's semicircular flap used for lid reconstruction

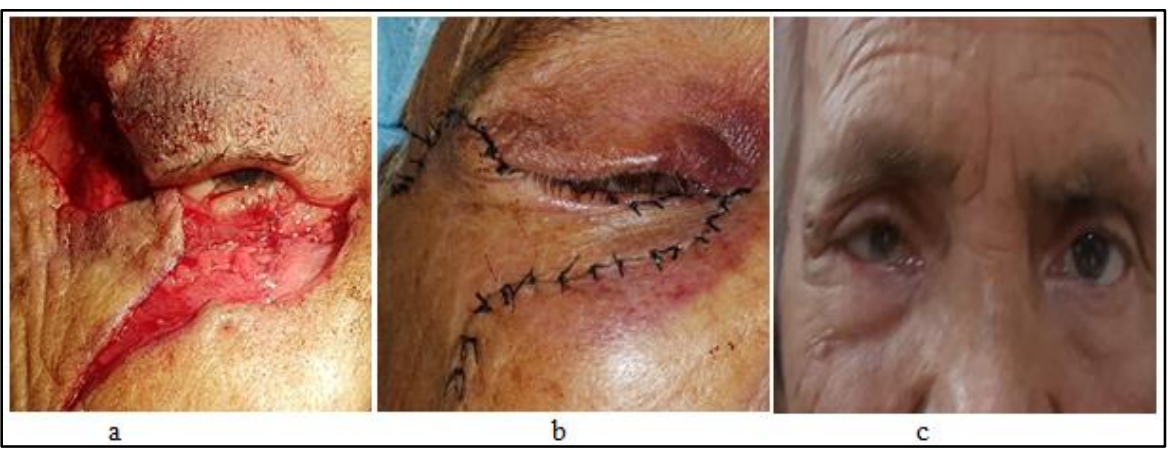

Fig-4a: Local advancement flap. 4b: Suturing of defect with complete lid reconstruction done. $4 \mathrm{c}: 4$ weeks postoperative

HPE of the lesion revealed a well-defined epidermal tumor with uniform small cuboidal epithelial cells with rounded deeply basophilic nuclei, inconsipicous nucleoli, few narrow ductal lumina, and occasional cystic spaces. The individual neoplastic cells had compact eosinophilic cytoplasm connected with the overlying epidermis. The tumour cells were sharply delineated from adjacent keratinocytes. Foci of squamous differentiation and clear cell change were commonly seen. The intervening stroma was characteristically very vascular. No atypical mitotic figures were encountered. Based on these findings, a diagnosis of eccrine poroma was made (Fig. 5).

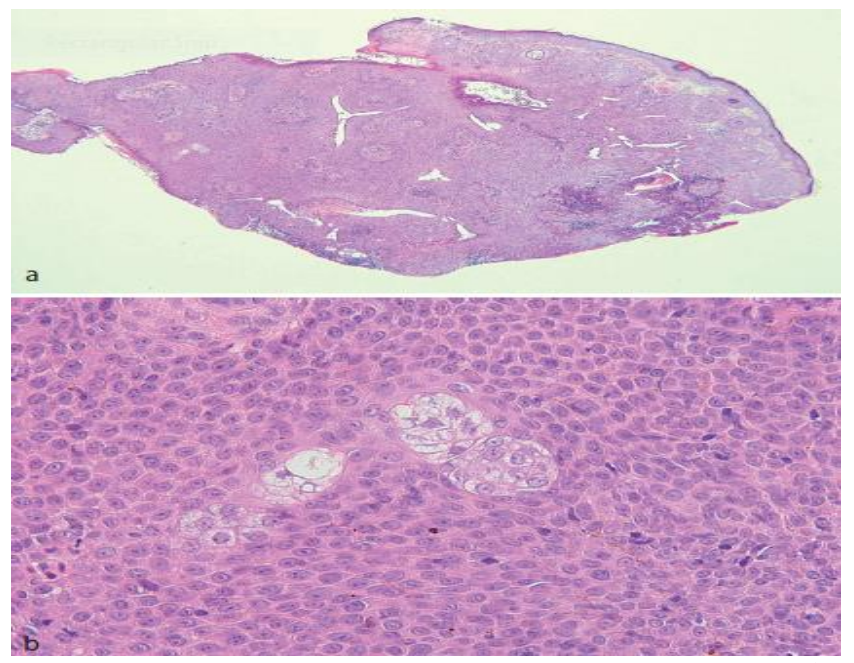

Fig-5a: HPE of specimen revealed well defined nests of monomorphous cuboidal poroid cells. Fig-5b: Sebaceous components were observed within the tumor nests 


\section{DISCUSSION}

Tumours of cutaneous sweat glands are uncommon, with a wide histological spectrum, complex classification and many different terms often used to describe the same tumour. Furthermore, the issue is complicated by the coexistence of eccrine and/or apocrine lesions within cutaneous hamartomas or within adnexal lesions with composite/mixed differentiation, which also includes those with follicular and sebaceous differentiation [2].

Eccrine sweat glands are widely distributed almost everywhere in the skin but are most abundant in the palms, soles and axilla. In the eyelid they are present both at the lid margin and in the dermis over the surface of eyelids. Apocrine lesions of the skin are rare and are found mainly in body folds including the axillary, groin and anogenital regions, where apocrine glands are most concentrated, as well as in the umbilicus, eyelid (Moll's glands), areola and in external auditory meatus[3].

Lever [4] classified sweat gland tumors into four groups on basis of proliferation - hamartomas, adenomas, benign epitheliomas and primary epitheliomas - but without taking account of sweat apparatus involved. This was considered by

Allen [5] who divided these tumors into two groups - ductal and glandular. These were further divided by eccrine and apocrine differentiation. Eccrine poroma fall into category of benign epitheliomas. Whatever classification or nomenclature is adopted, eccrine poroma remains an established clinicopathological entity with distinct histopathological appearance.

Eccrine poroma was first described by Goldman et al. [6] in 1956. The term 'poroma' refers to a group of benign adnexal neoplasms with 'poroid' or terminal ductal differentiation. Clinically, poromas usually present as solitary papules, plaques, or nodules usually over the palms and soles but may appear on any cutaneous surface where they tend to mimic benign and malignant melanocytic and non-melanocytic lesions. About two-third of cases $(65 \%)$ are seen on soles or sides of soles followed by hands (10\%) and fingers, and rarely over the face. Most of the lesions appear in middle-aged or elderly individuals [7, 8]. To our knowledge, benign eccrine poroma occurring on eyelid has been reported once before in the literature.

Clinically it may resemble a basal cell carcinoma.However, dermoscopic examination reveal pink to whitish, irregularly shaped structures composed of telangiectasia, fine hairpin-like vessels and some linear vessels (Fig. 2). Basal cell carcinoma usually shows arborizing vessels rather than fine hairpin-like vessels as in our case in dermoscopy. Altamura et al.
[9] also have recently reported polymorphous vascular patterns in eccrine poroma, on dermoscopy as seen in our case. Hence there were no dermoscopic findings suggestive of basal cell carcinoma in the present case. HPE findings also differentiated it from BCC.

Histologically, three main types are recognised and distinguished according to their location in relation to the epidermis: (1) poroma involving both epidermis and dermis; (2) hidroacanthoma simplex, also known as intraepidermal poroma, confined within the epidermis; and (3) dermal duct tumour, limited to the dermis, with no epidermal attachment. These tumours consist of solid sheets and nodules of basaloid poroid cells with pushing borders that emanate from the epidermis. The neoplastic cells are small, monomorphous and polyhedral cuboidal, with well-defined cell membrane. They have small, centrally located bland nuclei, and a variable amount of cytoplasm [3].

Eccrine poroma may exhibit polymorphic features that can make the diagnosis difficult. Forman et al. [10] in their article on eccrine poroma, described it as a tumor with many faces. Differential diagnosis of eccrine poromas described in previous case reports includes pyogenic granuloma, hemangioma, seborrheic keratosis, verruca, fibroma, melanoma, nevus, cysts, and basal and squamous cell carcinoma.However HPE findings are helpful in reaching to a conclusive diagnosis.

The prognosis of poromas is favourable because the lesions have no known clinical significance. Even poromatosis (multiple poromas) is not associated with other anomalies. The risk of malignant transformation of a poroma is minimal and is thought to be similar to that of normal skin.

In our case, eccrine poroma was found in the very unusual site, eyelid with symptoms such as bleeding and discharge. We suggest that this case contributes to the small part of literature on the potential for development of eccrine poroma on any skin surface area with sweat gland.

\section{CONCLUSION}

The lesion on our patient's eyelid which was masquerading as a cutaneous carcinoma clinically, proved to be an eccrine poroma histopathologically. Even though an eccrine poroma has typical histopathological features, it has a propensity toward varied clinical presentations. Hence, such atypical nodules require a biopsy for confirmation of diagnosis and further management. Enzyme immunohistochemistry and genetic studies help in typifying poromas better. Many cases of eccrine poroma have been reported. However none of these authors reported involvement of eyelids. The rarity of 
this tumor at this site made the present case worth reporting.

\section{REFERENCES}

1. Ahmed, T.S.S., Priore, J.D., Seykora, J.T. Tumours of the Epidermal Appendages. Elder DE, Rosalie E, Johnson BL, editors. Lever's Histopathology of the Skin. $10^{\text {th }}$ ed. Wolters Kluwer: Lippincott Williams and Wilkins, 2005. 885-8.

2. Ahluwalia, B. K., Khurana, A. K., Chugh, A. D., Mehtani, V. G. (1986). Eccrine Spiradenoma of eyelid: Case report. British Journal of Ophthalmology, 70:581-83.

3. Obaidat, N.A., Alsaad, K.O., Ghazarian, D. (2007). Skin adnexal neoplasms - part 2: An approach to tumors of cutaneous sweat glands. Journal of Clinical Pathology, Feb;60(2):145-159.

4. Lever, W.T. (1943). Myoepithelial sweat gland tumor, myoepithelioma: report of three cases with review of literature. Arch Dermatol, 5(3),32-47.
5. Allen, A.C.(1977). Skin. In: Anderson WAD, Kissene JM eds. Pathology. St. Louis: Mosby, 18, 66-70.

6. Goldman, P., Pinkus, H., Rogin, J.R. (1956). Eccrine poroma; tumors exhibiting features of the epidermal sweat duct unit. AMA Arch Derm, 74(5),11-21.

7. Agrawal, S., Kumar, B., Sharma, N. (2009). Nodule on the chest. Indian J Dermatol Venereol Leprol, 75:639. Ferrari, A., Buccini, P., Silipo, V., Simone, D. E. P., Mariani, G., Marenda S. (2009). Eccrine poroma: A clinical-dermoscopic study of seven cases. Acta Derm Venereol, 89:1-4.

8. Altamura, D., Piccolo, D., Lozzi, G.P., Peris, K. (2005). Eccrine poroma in an unusual site: a clinical and dermoscopic simulator of amelanotic melanoma. J Am Acad Dermatol, 53:539-541.

9. Forman, S.B., McMullan, F.H., Azmi, F.H. (2005). Eccrine poroma: One tumor, many faces. J Cutan Pathol, 32:7-8. 